\title{
CHARTING THE ANATOMY OF LINGUISTIC REALITY
}

\author{
R.P. Botha \\ Department of Linguistics \\ University of Stellenbosch
}

(Q1) represents the kind of question that should be addressed in the opening paper of a conference with the theme 'Linguistics for the language professions'.

(Q1) Has linguistics got anything to offer that can be of value to all language professions?

But (Q1) is a question that invites responses with potentially disastrous consequences. Obviously; nothing would be gained by saying in response to (Q1) things that were at once trivially and boringly true. Equally obviously, it would be counterproductive to respond to (21) by saying things that stretched people's credulity to the point of outraged disbelief.

Part of the problem with $(21)$ is that the label the language professions covers so much: all professions whose practitioners, on the basis of specialized knowledge, do something to one or more components of linguistic reality in order to achieve institutionalized ends. Indeed, the various language professions appear to differ so greatly in their specific aims and practices that one may question the sensibility of even raising $(Q 1)$.

A further part of the problem with (21) is that the term 1 inguistics, used in its 'macro' sense, is likewise an umbrella label. In this sense, linguistics covers, amongst other things, theories of linguistic structure, theories of language use, psycholinguistics, sociolinguistics, diachronic linguistics, clinical linguistics, text linguistics and much else besides. 
http://spilplus.journals.ac.za/

And so, in view of the many ways in which the various subfields of linguistics differ from each other, addressing ( 01 ) inust seem close to being an act of suicide. Any individual linguist, after all, is abie to find his/her way around in two or three of these subfields at the most. And yet, given my irveterate weakness for living dangerously, I am going to respond to (Q1) by attempting to show tiat there is something of consicierabie value that ingustics can of fer to all language professions.

2 ünderpinning practices with understanding

So let us consider a second quastion:

(Q2) What is tinis thing of value that linguistics

$\therefore$ can offer to all language professions?

The shoit answer to (22) is: a deeper understanding of the various reaims of linguistic reality ir thich ianguage professionals operate. But, notorjously, short answers (especially short answers in long words) invite more guestions, the first. or which ir the present case is:

(Q3) What does it mean to gain a deeper understanding of linguistic reality?

It means, minimally, that one has to acquire systematic knowledge of the following aspects of linguistic reality:

(AR1) the overall anatomy (or architecture) of linguistic reality,

(AR2) the general nature of each of the various components of linguistic reality,

(AR3) the specific properties of each of the components of linguistic reality, and

(AR4) the 'laws' governing linguistic reality. 
Indeed, without a sound understanding of these aspects of linguistic reality, linguistic professionals --- in pursuing their aims and conducting their practices --- face frustration and, ultimately, failure. I will illustrate this point with reference to two episodes from the history of second language teaching; the history of other language professions, however, will bear out the point too.

\subsection{Bungling things behaviouristically}

The first of my specimen episodes concerns the fate of methods of second language teaching aimed at furthering/facilitating memorization and habit formation. The teaching practices adopted in pursuit of these aims included drills, feedback ard reinforcement. The failure of these methods of second language teaching -.. including the so-called audiolingual metinod and programmed instruction --- has of course been extensively documented. 1

The pertinent question is: Why did these methods of secondlanguage teaching fail? The more or less generally accepted answer says, in effect, that they failed because they were based on false assumptions about linguistic reality. At a less deep level, there are various false assumptions about the nature of language acquisition. Three of these, as formulated by Rivers (1964), read as follows:

$$
\begin{aligned}
& \text { (AL1) 'Foreign-language learning is basically a } \\
& \text { mechanical process of habit formation.' } \\
& \text { (AL2) 'Habits are strengthened by reinforcement.' } \\
& \text { (AL3) 'Foreign-language habits are formed most ef- } \\
& \text { fectively by giving the right response, not } \\
& \text { by making mistakes.' }
\end{aligned}
$$

At a deeper level, the false assumptions (AL1)-(AL3) reduce to a flawed conception of what language is in essence. Rivers states the core of this conception of language as follows: 
(CL) 'Language is behavior'.

At a still deeper level, the conception of language (CL) reflects a failure to draw a fundamental distinction:

(ED) Language is distinct from language behaviour (or speech).

I have given elsewhere a detailed account of the flaws of the behaviourist conception of language. ". Reduced to the essence, these flaws include the failure of this conception of language to account for (a) the creativity of language use, (b) the freedom of language use from stimulus control, and (c) the fact that children acquire their native language on the basis of a stimulus that is both degenerate and impoverished.

To get back to the main point: the history of the audiolingual metrod and programmed instruction clearly shows the inevitable fate of methods of language teaching that are based on insufficient understanding of fundamental aspects of linguistic reality. And it is important to realize that there is no method of language teaching which is not based on assumptions about the nature and properties of language, about language acquisition, and about other components of linguistic reality.

\subsection{Confusing cognitive capacities}

But let us move on to an example of a second kind making it clear that language teachers have to understand the anatomy of linguistic reality in some depth. This example involves puzzling differences in performance between child and adult learners of the same second language. Thus, various SLA researchers have furnished evidence in support of the following finding: 
(F) Unlike child learners, adult learners frequently produce second language utterances which exhibit a minimal degree of syntactic structuring.

Before we proceed, let us note that (F) applies to an early stage of (naturalistic) second language acquisition.

To see what (F) is about, consider the utterances (U1)-(U6), taken from schumann's (1981) work: ${ }^{3}$

(U1) Is one man drink too much?

(There was one man who was drunk.)

(U2) And for work, in Mexico, for hour for the, 70 or 80 dollar, 80,80 peso for 8 hour. (As for the work in Mexico you get 80 pesos for 8 hours.)

(U3) This country, three year.

iss for this country, I have been a painter here for three years.)

(U4) ¿ day por week, 3 day por week, no long time. no good.

12 or 3 days a week is ok, but more than this is not good.)

(U5) In my apartment, no good. Good, good work every day.

(staying in my apartment is no good. It's good to work every day.)

(U6) Pero, mi study everbody more time, no? The schedule, the school, everybody mas long, no? The engineer, the doctor, muy good, no? Ver good for me. No money, no school.

(School takes a long time. It would be very good to be a doctor or an engineer. But without money you can't go to school.) 
Other than some loose paratactic juxtapositioning, utterances such as (U1)-(U6) do not show more than a minimum of syntactic structure. Rather, they seem to be formed on the basis of general conceptual or semantic patterns, including the topiccomment configuration. Even in an early acquisitional stage, child SL learners, by contrast, produce utterances with clearly recognizable syntactic structures. The child utterances, however, generally lack the semantic complexity exhibited by (U1)-(U6).

The question, of course, is: why do the utterances produced by adult second language learners and those produced by child second language learners differ in syntactic and semantic structure? A plausible answer. -- suggested by researchers such as Felix (1985, 1986), Zobl (1989) and White (1989) -.is based on the assumption that at least two cognitive faculties are involved in second language acquisition, known as 'the IS-system' and 'the PS-system'. 'lhe LS-system --- also called the 'language faculty' or 'universal grammar'4 represents man's innate cognitive capacity for acquiring language. It is a domain-specific system, neurally hard-wired for the acquisition of language and language alone. The PSsystem -.. also called a 'central processor' or 'central system. 5 -.- represents a cognitive faculty used by humans for problem-sclving in general. As such, the PS-system is not domain-specific and not neurally hard-wired for performing a single specific task only.

The LS-system, it is claimed, functions optimally until the onset of puberty. It constitutes the basic cognitive mechanism used by children for both first and second language acquisition. The properties of this system enable children to acquire such abstract formal operations as syntactic rules relatively effortlessly. This is why the utterances they produce, though semantically on the whole relatively simple, exhibit clear syntactic structuring.

The PS-system, by contrast, starts to function fully after the 
onset of puberty -.. in what Piaget has called 'stage IV'. The PS-system is claimed to play a major role in adult second language acquisition, though the LS-system seems to keep playing some role. Being designed for general problem-solving, the PS-system is not good at the acquisition of such abstract formal operations as syntactic rules. Consequently, adult learners of a second language have to rely, initially at least, on general problem-solving strategies for forming L2 utterances. Hence, these utterances, though semantically complex, exhibit little syntactic structuring.

So, and this is the point, to understand basic differences between SL utterances produced by child learners and SL ut terances produced by adult learners, a language teacher has to have a more than superficial insight into the anatomy of linguistic realj.ty. Minimally, he/she has to know that ihis reality contains at least two cognitive faculties which are involved in language acquisition. And he/she has to have a fairly good idea of the properties of those faculties.

Incidentally, the assuption that (at least) two cognitive faculties are involved in language acquisition provides a basis for understanding a further puzzling acquisitional phenomenon as well. Researchers and teachers have been puzzled for quite a while by the phenomenon which may be described as in ( $P A)$ :

(PA) Environmental and personality factors crucially affect adults' acquisition of a second language, yet these factors have little or no effect on the way in which people acquire their first language during childhood.

The factors alluded to in (PA) include motivation, affective and attitudinal conditions, social status, educational background, cultural values and so on.

As argued by Felix (1985, 1986), for example, an understanding 
of the differences between the PS-system and the LS-system makes it possible to propose a plausible solution to the puzzle under consideration. Being a central processor, the PS-system by its very nature is open to the influence of a wide variety of factors. The LS-system, by contrast, being a hard-wired domain-specific system, is insensitive to environmental and personality factors. Hence, whereas such factors affect adult language acquisition mediated by the PS-system, they do not affect child language acquisition mediated by the Ls-system. 6

This brings us to the all-important question:

(24) In what ways can linguists assist practitioners of the language professions to increase their understanding of the anatomy of $l$ inguistic reality?

in the remaining part of my paper, I would like to outline one of triese ways. This way, in essence, calls for linguists to furnish language professionals with a revealing chart of linguistic reality, a chart that insightfully maps the aspects of linguistic reality listed above as (AR1)-(AR4).

Obviously, within the restricted scope of this paper, I cannot present a detailed chart of linguistic reality. At most, I can sketch the outlines of such a chart and illustrate how these outlines can be filled in with at least some details.

\subsection{Laying bare the bones}

A good chart of the anatomy of any reality has to lay bare its skeleton. So, what are the bare bones of linguistic reality? These bare bones are individuated in the following general beliefs or assumptions: 
(B1) Linguistic reality is composed of things that are involved in acts, events and processes.

(B2) The various components of linguistic reality have properties that characterize them in respect to substance, form, structure, function, etc.

(B3) Smaller components of linguistic reality are organized into such bigger components as systems, modules, etc.

(B4) The components of linguistic reality ---' both the bigger and the smaller ones --- are interconnected and interact with each other.

(B5) Linguistic reality has interfaces with other realities with which it. interacts.

(B6) The components of linguistic reality are governed by various kinds of 'laws'.

(B7) The make-up and properties of some of the components of linguistic reality are affected by agents who deliberately intervene from outside.

As is clear from Mario Bunge's (1977, 1979) systemic ontology, the beliefs (B1)-(B7), reduced to their essence, are not specifically linguistic. Suitably rephrased, they hold for nonlinguistic realities too. But to get back to the point, in terms of the beliefs (B1)-(B7), the bare bones of linguistic reality include such categories of entities as those listed in $(B B)$ :

(BB) things, acts, events, processes, interactions, systems/modules, interfaces, interventions,

'laws'

In technical terms, these bare bones have been called 'ontological categories'. 


\subsection{Putting some flesh on the skeleton}

But how are the listed ontological categories realized or manifested in linguistic reality? This question calls for a fleshing out of the skeleton of linguistic reality.

So let us begin by considering representative instances of things clained to form part of linguistic reality. In (T1)-(TA) I list. a number of typical examples of linguistic things. (None of the lists furnished in this paper pretends to be exhaustive; ail are illustrative only.)

(T1) forms of language(s): language in general, individual languages, various kinds of varieties and 'lects' (e.g., dialects, sociolects, idiolects), standard languages, lingua francas, sub- . languages, marginal languages (e.g. pidgins, broken languages), creoles, interlanguages, proto-languages, sign languages

(T2) people: (ordinary) speaker-hearers, 'special' users of language (e.g., writers, ieaders, interpreters, translators, signers, lipreaders, etc.), (natural) language acquirers, (instructed) language learners, various kinds of linguistic groups and communities

(T3) Iinguistic faculties, capacities and mechanisms: the language (acquisition) faculty, knowledge of language, grammatical competence, pragmatic competence, the ability to use language, fluency, parsing mechanisms, mechanisms of speech production, literacy, bilingualism, diglossia

(T4) products of language behaviour: utterances, intuitive linguistic judgements, texts, conversations, discourses.

A useful chart of linguistic reality will not merely individuate and locate the things believed to form part of linguis- 
http://spilplus.journals.ac.za/

tic reality. It will, in addition, clarify the nature of. (candidate) things by characterizing them in terms of relatively basic distinctions such as those exemplified in (DT1)(DT14).

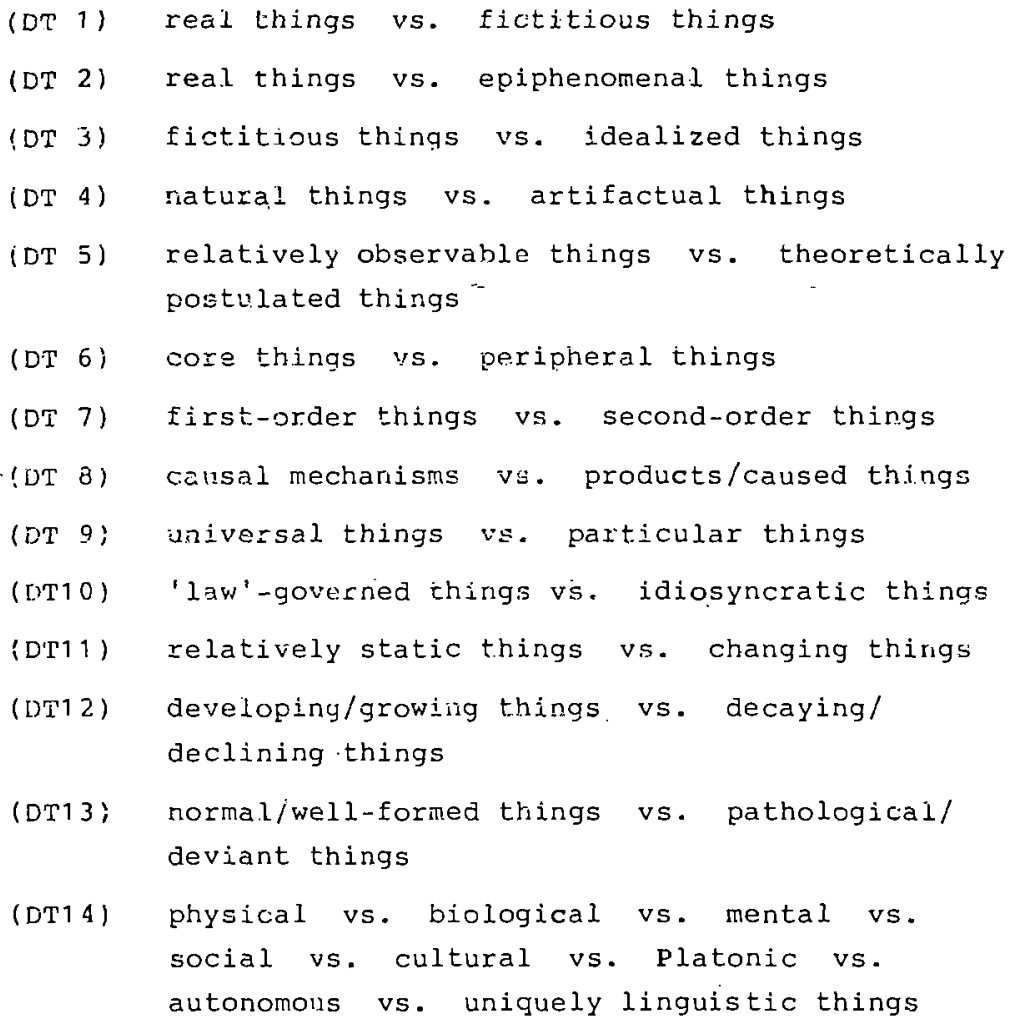

Each term of distinctions such as (DT1)-(DT14) provides for a potentially fundamental characteristic of some (candidate) linguistic thing.

Having considered some examples of linguistic things of various kinds, let us next turn to those linguistic entities that make linguistic reality as dynamic as it is. A first kind of these entities are acts. In (LA), I list a variety of typical acts occurring in linguistic reality. 
(LA)

$$
\begin{aligned}
& \text { 'speaking, hearing, writing, reading } \\
& \text { 'speaking to the (partially) deaf, lipreading } \\
& \text { 'signing, 'seeing' signs } \\
& \text { 'speaking to oneself, to animals or to inani- } \\
& \text { mate objects, 'thinking' aloud } \\
& \text { 'speaking to person } P \text { by addressing person } Q \\
& \text { otranslating and interpreting (not only from } \\
& \text { language A into language B but also from lect } \\
& \text { register / variety C of language A into lect } \\
& \text { register / variety D of language A) } \\
& \text { 'singing, reciting, intoning, chanting } \\
& \text { 'speaking in public, preaching, ' town crying' } \\
& \text { obroadcasting, giving sports commentaries } \\
& \text { (e.g., on horse racing), auctioning } \\
& \text { 'fighting/dueiling verbaily, mimicking, playing } \\
& \text { with language } \\
& \text { Jjudging properties of utterances intuitively }
\end{aligned}
$$

In a good chart of lirguistic reality, the nature of linguistic acts such as those listed in (LA) will be clarified with the aid of various sets of distinctions. A first set provides a basis for characterizing linguistic acts in terms of their function. These distinctions are based on the various functions in or purposes for which language can be used. In (Fi)(F13), I list some of these functions:

\footnotetext{
(F 1) communicating thoughts, desires, feelings, etc.

(F 2 ) expressing emotions (e.g., by swearing, exclaiming, etc.)

(F 3) thinking/organizing thought

(F $\leq$ ) representing reality mentally

(F 5) structuring perceptions of reality

( $\dot{F}$ 6) controlling reality (supernaturally)
} 
(F 7$)$ doing institutionalized deeds (e.g.., sentencing, christening)

(F 8) structuring activity (e.g., in work or play)

(F 9) expressing identity (e.g., physical, psychological, geographical, ethnic, social, occupational)

(F10) creating products with aesthetic properties, performing aesthically

(F11) recording 'the facts'

(F12) describing/commentating on events, etc.

(F13) establishing or maintaining (good) social relations

A second set of distinctions allows for linguistic acts having a commuricative function to be further characterized. These distinctions have import of a semiotic kind, bearing, for exanple, on the number of codes invoived, the charactexistics of speakers as senders and hearers as receivers, the nature of the medium and channel used, and so on.

But let us proceed to a second kind of entities that contribute to the dynamics of linguistic reality: processes. In (P1) and (P2), I list examples of two of the kinds of processes believed to form part of linguistic reality.

(P1) processes affecting (forms of) language(s)

ovolving in the species, changing in time, being born (e.g., pidginization), growing rapidly (e.g., creolization)

'declining in a group/community, becoming less unique/individual (e.g., decreolization), committing suicide, being murdered

obecoming/being standardized, becoming more different/more highly individuated 
(P2) processes affecting (individual) speaker-hearers oacquiring a language (naturally), becoming bilingual/diglossic, becoming more fluent, becoming literate (naturally)

'declining in respect to competence, fluency, etc. (e.g., through ageing), loosing control over production and perception mechanisms (e.g., as a result of illness/trauma;

obeing taught a (first, second, ...) language or a form (e.g., a lect, style, register) of language, undergoing literacy training, receiving speech therapy.

Obviuusly, some of the processes listed in (P1) and some of those listed in (P2) are interreiated. Details of such interrelations are, however, beyond the restricted scope of this paper. In general, though, no process can affect (forms of) language(s) without affecting individuaI speaker-hearers. By contrast, certain processes affect individual speaker-hearers without necessarily affectirig (forms of) language(s).

A good chart of linguistic reality will elucidate the nature of processes such as ( $P 1$ ) and (P2) by bringing to bear on them distinctions such as the following:

(DP 1) processes affecting (forms) of language(s) vs. processes affecting individual persons (targets)

(DP 2) local processes vs. global processes (scope)

(DP 3) slow processes vs. fast processes (tempo)

(DP 4) short processes vs. long processes (duration)

(DP 5) immanent processes vs. interventionist processes (orgin)

(DP 6) natural processes vs. nonnatural processes

(DP 7) cause-driven processes vs. target-seeking processes 
(DP 8) destructive/disruptive processes vs. constructive/restorative processes

(DP 9) processes creating diversity vs. processes creating similarity/homogeneity

(DP10) processes below the level of consciousness vs. processes above the level of consciousness

(DP11) physical processes vs. biological processes vs. ...... (cf. DT14 above)

Again, each term of distinctions such as (DP1)-(DP11) individuates a property that may be important in understanding a particular linguistic process.

We come next to a third category of 'dynamic' entities that contribute to the make-up of linguistic reality: interactions taking place among the various kinds of linguistic entities. The different kinds of interactions occurring within linguistic reality are too numerous to survey, even superficially, here. In (IA1)-(IA5), I list a few simple examples, purely for the sake of illustration:

(IA1) In interpreting utterances: grammatical competence, pragmatic competence, conceptual systems (of knowledge and belief), and parsing mechanisms interacting with each other

(IA2) In producing complex texts: immanent linguistic 'laws' (principles, rules) interacting with imposed (stylistic, etc.) norms

(IA3) In acquiring a first language: innate/universal linguistic principles interacting with utterances of the language in question

(IA4) In pidginization: universal linguistic principles interacting with structures/rules of superstrate and substrate languages 
(IA5) In language change: social triggers interacting with psychological causes

For elucidating the nature of the interactions occurring within lingiristic reality, a good chart of linguistic reality will use distinctions such as those listed in (DI1)-(DI4):
(DIi) conspiring vs. competing vs. conflicting
(DI2) triggering vs. shaping
(DI3) initiating vs. inhibiting vs. blocking
(DI4) strengthening vs. interfering vs. weakening

Interactions, of course, occur not only within linguistic reality but also at the interfaces where it interacts with other realities.

This brings us to another kind of the bare bones forming the skeleton of linguistic reality: interfaces. For the sake of illustration, I list a number of typical examples of such interfaces in (IF1)-(IFB).

(IF1) linguistic reality $\leftrightarrow$ physical reality (including sound)

(IF2) linquistic reality $\rightarrow$ biological reality (incorporating anatomical, neurological, genetic entities)

(IF3) linguistic reality $\leftrightarrow$ (non-linguistic) psychological reality (incorporating memory, attention, etc.)

(IF4) linguistic reality $\leftrightarrow$ conceptual systems (including systems of knowledge and belief)

(IF5) linguistic reality $\leftrightarrow$ social reality (incorporating groups) 

(IF6) linguistic reality $\longleftrightarrow$ aesthetic value systems (in- volved in the production/re- ception of texts, in reciting, in singing, etc.)

(IF7) linguistic reality $\longleftrightarrow$ ethical value systems (bearing on language ecology/linguistic hygiene)

$\begin{aligned} & \text { (IF8) linguistic reality } \longleftrightarrow \text { cultural reality (reflected in } \\ & \text { writing systems, etc.) }\end{aligned}$

Interactions, both those internal to linguistic reality and those occurring at such interfaces as (IF1)-(IF8), figure crucially in the performing of complex linguistic acts.

The kinds of acts, processes and interactions that I have exempiified above contribute to what constitutes the natural or immanent aynamism of linguistic reality. There is another sense, however, in which linguistic realjty may be said to be 'dynamic': it is the target of interventions initiated from outside. That is, agents from outside can act on linguistic reaity with the aim of affecting it in certain ways: changing properties of its components, triggering/influencing/inhibiting linguistic acts and processes, etc. In (IN1)-(IN11), I list a few examples of such interventions:

(IN1) teaching/instructing (varieties of) languages to people

(IN2) giving people literacy training

(IN3) treating people for linguistic pathologies/ deficits

(IN4) editing texts

(IN5) creating new (technical) terminologies or entire sublanguages

(IN6) standardizing languages/dialects 
(IN 7) prescribing norms for various forms of language use

(IN B) practising linguistic hygiene (e.g., combating the immoral use of language (as for deception or oppression))

(IN 9) trying to expunge so-called impurities (e.g., foreign words, isms, etc.) from languages

(IN10) irying to arrest and/or reverse linguistic changes (IN11) trying to murder a language or lect

Or a good chart of linguistic reality, interventions such as those listed in (IN1)-(IN11) should be insightfully characterixed with the aid of distinctions bearing on the status of the agents and the nature of their aims, on the scope of the interventions, on the nature of their effects, and so on. As for agency: some interventions are performed on a principled basis by, For example, teachers; translators, speech therapists, and so on, who have a nonsuperficial understanding of linguistic reality. Other interventions, by contrast, are arbitrary acts performed by an assortment of quacks, shamans, ideologues and so on.

Linguistic reality is a complex and crowded realm. This is what appears even from the chart which I have only been sicetching in outline above. But to say that linguistic reality is a complex and crowded realm is not to say that it is a chaotic realm. At a deeper level, on the contrary, linguistic reality is characterized by a high degree of regularity, order and organization. This is due to the fact that linguistic reality incorporates a further fundamental category of entities: lawlike entities such as the following:

(L) 'laws', principles, general conditions, rules, norms 
Nomic/Normative entities such as these govern the other components of linguistic reality: the things, the processes, the acts, and so on. The nature and properties of lawlike linguistic entities should, on a proper chart of linguistic reality, be clarified with the aid of distinctions such as those listed in (DN1)-(DN5):

(DN1) immanent principles vs. imposed norms

(DN2) (deep) deductive principles vs. (shallow) inductive generalizations

(DN3) universal principles vs. typological tendencies vs. language-specific rules

(DN4) deterministic laws vs." probabilistic laws

(DN5) causal laws vs. non-causal laws

\subsection{Focussing on finer fibres}

The outline form in which I have been sketching the chart of linguistic reality is no more than an incomplete, coarsegrained approximation. It has to be filled in and refined in many ways. Let me illustrate this point with the aid of two examples.

In (LA) I listed examples of the acts that occur in linguistic reality. The first was speaking. But, as Levelt (1989:8ff.) has shown, speaking is a highly complex act made up of various sub-acts, including those listed in (SA):

(SA) message generation, grammatical encoding, phonological encoding, articulating, selfmonitoring

To give you some idea of how these sub-acts jointly making up speaking hang together on a more finely-grained chart of lin- 
guistic reality, I represent Levelt's (1989:9) 'Blueprint for the speaker' as (BS).

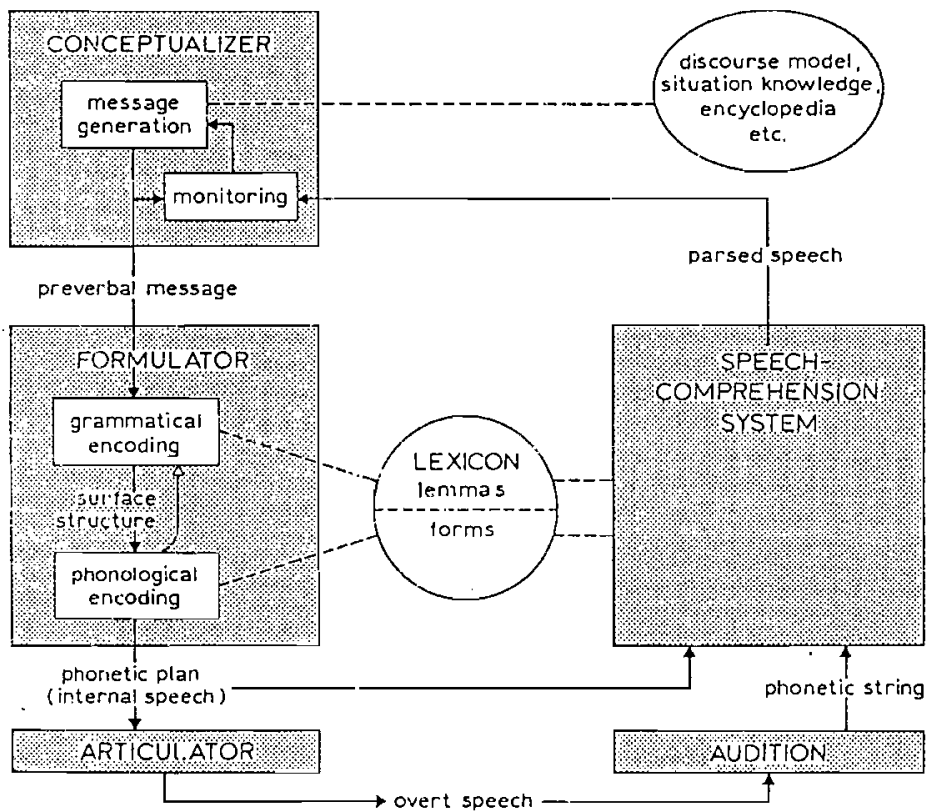

Boxes represent processing components; circle and ellipse represent knowledge stores.

Even Levelt's 'Blueprint', however, still presents only a rough picture of the make-up of speaking. For, as he goes on to show in his book, each of the sub-acts listed in (SA) is, in its turn, made up out of more elementary components. The general point is that, like speaking, nearly everyone of the linguistic acts listed in (LA) represents a cluster or system of more elementary entities that have to be specified on a good chart of linguistic reality. And the same goes for the linguistic processes enumerated in (P1) and (P2), and also for the 
linguistic things exemplified in ( $\mathrm{T} 1)-(\mathrm{T} 4)$.

Recall that systems, modules, etc. have been identified in (BB) above as representing one of the major kinds of bare bones making up the skeleton of linguistic reality. Perhaps the best-known examples of linguistic (sub-) systems are the sets of rules that have been taken to make up grammatical com-. petence. These include:

(RS) syntactic rules (including base and transformational rules), morphological rules, phonological rules, rules of logical form, etc.

But let us consider a second example illustrating the incompleteness of the chart outline that I have been sketching. For this example, consider again the list of faculties, etc. listed above as (T3). This list contains only one faculty involved in language acquisition: the language (acquisition) faculty. But, as we have seen, it is quite likely that there are others, as is indicated by certain differences between second-language acquisition by children and second-language acquisition by adults. Recall that on his chart of this area of linguistic reality, Felix (1986:168) assigns a prominent place to the language (acquisition) faculty or Ls-system. In addition, however, he provides for at least five other mechanisms that play a role in second-language acquisition: the PS-system (a 'central cognitive processor'), a 'PSfilter', a 'cognitive output mixer', a 'monitor' and 'communication strategies'. The ways in which these mechanisms interact are charted by Felix (1986:168) with the aid of the following diagram: 
(CP) COGNITIVE PROCESSING IN LANGUAGE ACQUISITION

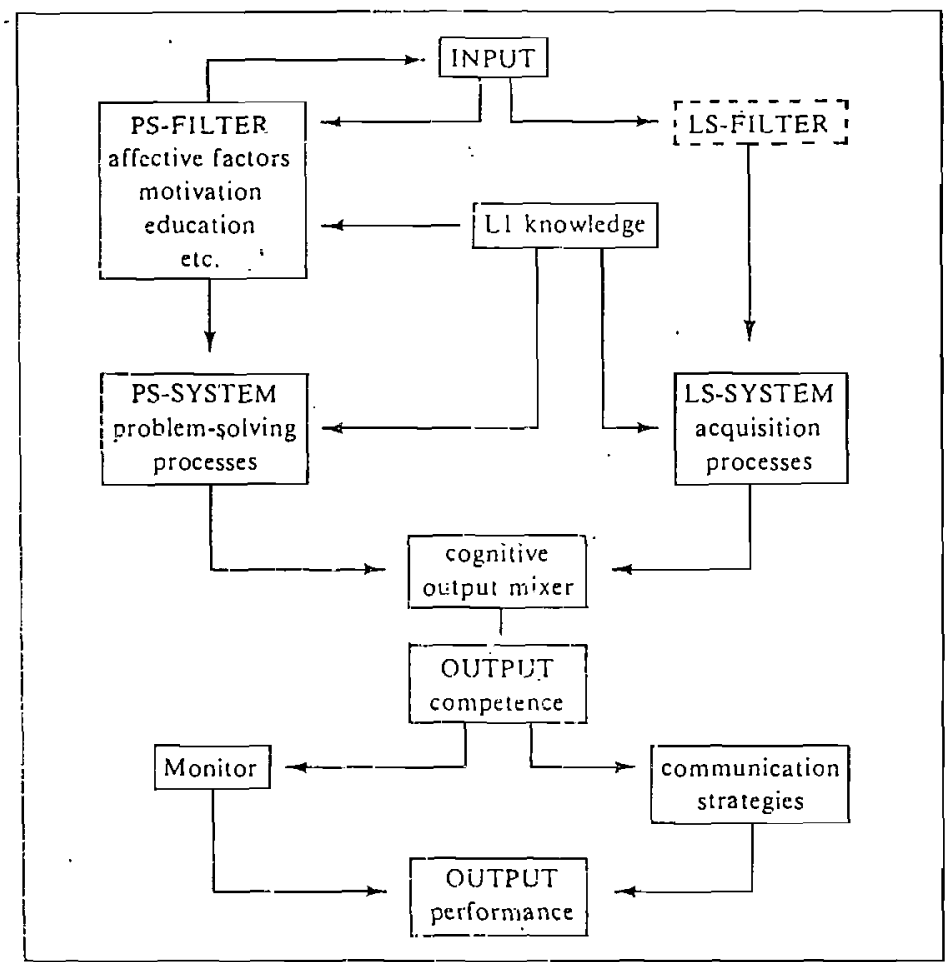

Whether all the additional mechanisms provided for by Felix do indeed form part of linguistic reality is an open question. But the belief that more than one faculty or cognitive mechanism is involved in second-language acquisition is held today by many SLA researchers.

Even the best chart of the anatomy of linguistic reality that linguists could draw at present would in many ways be insufficiently fine-grained. This is so because linguists to date have explored many areas of linguistic reality no more than in part. In this connection, it is important to understand, moreover, that the vast majority of the entities making up linguistic reality do not have the concreteness of bones, muscles, 
sinews, veins and bodily organs. Unlike such anatomical entities, the vast majority of linguistic entities are not there to see or touch. The majority of these entities, indeed, cannot be observed or inspected in any direct way. Their properties, their nature and, indeed, their very existence are established indirectly only --- that is to say, by means of complex chains of inferences. This goes some way towards explaining why linguists often disagree amongst themselves about whether a particular entity does or does not exist as part of linguistic reality. This, however, is not something to feel upset about. The history of advanced sciences such as physics yields many instances of disagreements of just this sort.

\section{Trading in tricks}

At this point, I would like to consider briefly a kind of aid that Iinguists should be quite hesitant to offec to their colleagues j.n the language professions. This is the kind of aid that consists in dispensing bags of tricks, kits of trendy tools, instant cures, quick-fix recipes, with-it ways of working wonders, and the like. To be more specific: Linguist A should think twice before offering language teachers a 'modern methodology; that would solve vexing problems of second-language teaching in a wink, yielding a measure of success unheard of before. Similarly, linguist $B$ should resist the temptation to sell his/her translator colleagues 'just the right recipe' for solving translation problems of a particularly recalcitrant type, say problems involving semantic voids. And, to use one more example, linguist $C$ should not be all that keen to press on speech therapists a 'particularly promising' procedure for diagnosing, for example, grammatical or pragmatic deficits of some less superficial sort.

Why should linguists think twice before offering their colleagues in the language professions 'miracle means' of doing difficult things? For two reasons essentially. As for the first, if linguists are specialists in anything, it is in one 
or two subfields of linguistics. And keeping reasonably well-informed about developments in a fast.-moving subfield is --- except in the case of linguists who are intellectual giants -.- a full-time job. This means that few linguists have the time to get to the bottom of the more taxing problems which expert language teachers, transiators, speech therapists and other language professionals have to deal with. There are of course some truly versatile'linguists who have gained a good understanding of these problems. I am thinking in particular of those linguists whose career experience includes a stint as a full-time practitioner of some language profession. But these linglists normally have learned from experience that such problems, being less than trivial, are resistant to easy, quick-fix solutions.

Which brings me to the second reason why linguists should not be into miracle mongering. To offer language professionals bags of tricks is to express indirectly a quite negative judgement on their. intellectual status. Specifically, these proFessional peuple ase assigned the status of grease monkeys: people who mechanically fix things or tinker with things without really understanding how these things work and without having much interest in the limitations of their tools. But the portxayal of practitioners of the language professions as mindless mechanics, surely, is false. There are various kinds of evidence that many language professionals value intellectual depth and that they are seriously concerned with gaining increased understanding of the foundations of their professions. Many, in addition, have shown themselves to be capable of critically appraising the approaches, practices and methodologies used in their professions. Armed with a good understanding of the aspects of linguistic reality listed as (A1)-(A4), practitioners of the language professions are quite capable of devising more effective ways, means, methods, strategies, and so on, of doing their thing.

There is particular point that has to be stressed: to say that linguists shoula refrain from offering language profes- 
sionals bags of tricks is not to say that, in principle, linguists cannot contribute highly specific ideas to particular language professions. Clearly, a distinction should be drawn between a trick and a specific suggestion or idea grounded in solid knowledge. What is wrong with a trick is not that it is specific, concrete, or. the like. What is wrong with a trick, rather, is that it is divorced from a good understanding of the nature of the problem at hand and, crucially, of the nature and properties of the linguistic entities involved in the problem. So, if during this conference, linguists were to argue that a particular well-founded linguistic concept or idea may be quite useful to certain language professionals, these linguists would be doing a perfectly respectable thing. There is a world of difference between, on the one hand, pointing out the potential usefulness of specific well-grounded linguistic idea and, on the other hand, foisting a 'foefie' on colleagues. 7

5 Ending on a nitty-gritty note

The final question that I would like to consider is of a practical sort:

(Q5) In what form could a reasonably detailed chart of linguistic reality be acquired?

Unfortunately not in the form of a colourful diagram, drawing or picture that may be bought over the counter. As I have used the expressions 'chart' and 'map', they obviously are metaphors. And, sadly, there is no single textbook, introductory or advanced, that offers a properly integrated and wellbalanced account of the anatomy of linguistic reality as a whole. The available textbooks --- and there are quite a few -.- have simply not been written from the ontological perspective that I have tried to present in this paper. 8 
So where does this leave languege professionals who wish to increase their understanding of the anatomy of linguistic reality? Well, they could either try under their own steam to extract such a picture from the numerous technical writings that deal with specific components of linguistic reality. Or, should they prefer not to engage in an exercise of self-imposed back-breaking, they could look for a linguistics course that did the extraction and (re-)assembly job for them. Fortunately, there are linguistics courses that are aimed at, anongst other things, providing an insightful account of the anatomy and dynamics of linguistic reality. Practitioners of the language professions could do worse than to inspect the wares offered in courses of this sort.*

*I am grateful to Walter Winckler for his expert editing of this paper. 


\section{NOTES}

1. Cf. Newmeyer 1983:140ff. and the references cited there.

2. Cf., e.g., Botha 1989b; 1990; in press: chap. 3 .

3. Pienemann (1980) and Dittmar (1982) have furnished similar examples of German utterances produced by adult language learners.

4. Cf., e.g., Chomsky 1986:25-26; Botha 1989a:25ff.

5. Cf. Fodor 1983:38ff.

6. Against the background of the distinction between the PSsystem and the LS-system, Felix (1986:162-163) suggests an interesting cause for the failure of traditional formal L2 instruction: 'Formal language instruction typically taps potentials of the PS-system and it has notoriously failed to produce the kind of learning success that it aims at. The notion of competing cognitive systems explains why the traditional kind of language instruction is bound to fail. Teachers are trained to make every effort to suppress operations of the LS-system because this would regularly and quite naturally produce (developmental) errors which, from the perspective of behavioristic learning theories, are seen as the major obstacle to learning success. Teachers will thus strongly encourage the student to activate as much of his PS-potential as possible in dealing with the learning task. In contrast, naturalistic language environments seem to be more conducive to strengthening operations of the LS-system than are formal classroom settings. In fact, it is commonly recognized that when a student exposed to formal teaching for a number of years is placed into a naturalistic language situation for a certain period of time (e.g. spending his vacation in the L2 country) he will, in most cases, significantly 
improve his command of the language. One might surmise that this is the case because, in such a situation, the LS-system will be given a fair chance to operate, while this is generally not the case under classroom conditions.'

7. The 'mechanics' of the suggestopaedic approach to language teaching incorporates various elements that are strong candidates for 'foefie' status. For a survey of these 'mechanics' cf. L. Botha 1990:39ff.

8. My colleagues and $I$ are working on a textbook (for Blackweij.) that is aimed at, anongst other things, providing an integrated account of the anatomy of linguistic reality This account should be informative not only to students of linguistics but to practitioners of the language professinns as well. 
REFERENCES

Botha, L. 1990. Suggestopaedia in theory and practice. Per Linguam, Special Issue No. 4:5-71.

Botha, R.P. 1989a. Challenging Chomsky. The Generative Garden Game. Oxford: Basil Blackwell.

Botha, R.P. 1989b. The Metaphysics Market: 1 Merchandizing Language as Matter. (SPIL 20). Stellenbosch: Department of General Linguistics.

Botha, R.P. 1990. The Metaphysics Market: 2 Billing Language as Behavioural. (SPIL 21). Stellenbosch:

Department of General Linguistics.

Botha, R.P. in press. Twentieth Century Conceptions of Language. The Metaphysics Market. Oxford: Basil Blackwell.

Bunge, M. 1977. Treatise on Basic Philosophy. Volume 3. Ontology I: The Furniture of the World. Dordrecht/ Boston: D. Reidel Publishing Company.

Bunge, M. 1979. Treatise on Basic Philosophy. Volume 4. Ontology II: A World of Systems. Dordrecht/Boston: D. Reidel Publishing Company.

Chomsky, N. 1986. Knowledge of Language: Its Nature, Origin and Use. New York: Praeger.

Felix, S.W. 1985. More evidence on competing cognitive systems. Second Language Research 1:47-72.

Felix, S.W. 1986. Cognition and Language Growth. Dordrecht: Foris Publications.

Fodor, J.A. 1983. The Modularity of Mind. An Essay on Faculty Psychology. Cambridge: MIT Press. 
Levelt, W.J.M. 1989. Speaking. From Intention to Articulation. Cambridge: MIT Press.

Newmeyer, F.J. 1983. Grammatical Theory. Its Limits and its Possibilities. Chicago: University of Chicago Press.

Rivers, W. 1964. The Psychologist and the Foreign-language Teacher. Chicago: University of Chicago Press.

Schunain, J. 1981. Non-syntactic. speech in the Spanish-English Basilang. Paper presented at the European-North American Workshop on Second I,anguage Acquisition Research, Lake Arrowhead.

White, I. 1989. Universal. Grammar and Second Language Acquisition. Amsterdam: Benjamins.

Zobj, H. 1989. Modularity in Aault L2 Acquisition. Language Jearning 39:49-79. 